\title{
A precarização do trabalho e da qualidade de vida do trabalhador paulistano na redemocratização
}

La précarité du travail et la qualité de vie des travailleurs de São Paulo en matière de redémocratisation

La precarización del trabajo y da calidad de vida del trabajador en São Paulo en la redemocratización

The labor precariousness and Labor quality of life in São Paulo at redemocratization

\section{Cristiane Fernandes de Oliveira, Camila Pinheiro dos Santos e Paula} Vitória de Faria Santos

\section{(2) OpenEdition}

\section{Journals}

Edição electrónica

URL: http://journals.openedition.org/espacoeconomia/7377

DOI: $10.4000 /$ espacoeconomia.7377

ISSN: 2317-7837

Editora

Núcleo de Pesquisa Espaço \& Economia

Refêrencia eletrónica

Cristiane Fernandes de Oliveira, Camila Pinheiro dos Santos e Paula Vitória de Faria Santos, «A precarização do trabalho e da qualidade de vida do trabalhador paulistano na redemocratização », Espaço e Economia [Online], 15 | 2019, posto online no dia 28 outubro 2019, consultado o 05 novembro 2019. URL : http://journals.openedition.org/espacoeconomia/7377 ; DOI : ERREUR PDO dans / localdata/www-bin/Core/Core/Db/Db.class.php L.34 : SQLSTATE[HY000] [1040] Too many connections

Este documento foi criado de forma automática no dia 5 novembro 2019.

(c) NUPEE 


\title{
A precarização do trabalho e da qualidade de vida do trabalhador paulistano na redemocratização
}

\author{
La précarité du travail et la qualité de vie des travailleurs de São Paulo en \\ matière de redémocratisation \\ La precarización del trabajo y da calidad de vida del trabajador en São Paulo en \\ la redemocratización \\ The labor precariousness and Labor quality of life in São Paulo at \\ redemocratization
}

Cristiane Fernandes de Oliveira, Camila Pinheiro dos Santos e Paula Vitória de Faria Santos

\section{Introdução}

1 A leitura do trabalho de Kowarick e Campanário (1984) inspirou a realização deste trabalho, no sentido que, a princípio instigou a curiosidade sobre sua metodologia adotada para avaliar a qualidade de vida do trabalhador no período de 1960 a 1991.

Nesta obra os autores buscam fazer uma análise dos dados sobre o tempo gasto em trabalho para o trabalhador adquirir a cesta básica e sobre a evolução do salário mínimo em comparação ao processo de crescimento do preço da terra, bem como em comparação ao processo de espoliação urbana para compreender de que forma o trabalhador sofreu grandes perdas na denominada "década mais que perdida". Deste modo, estas análises impulsionaram o desenvolvimento da pesquisa que embasa este artigo. Se procurou seguir a mesma metodologia dos autores citados com a análise dos mesmos condicionantes em um período mais recente, ou seja no período que envolve a chamada redemocratização, ou seja, entre 1995 e 2018.

Para o desenvolvimento da pesquisa foram efetuadas buscas de informações sobre a evolução do salário mínimo, sobre o tempo de trabalho para obter a cesta básica, sobre 
o custo da cesta básica e sobre a evolução do preço da terra no Município de São Paulo. Deste modo, a argumentação partiu do estudo da apresentação de dados concretos sobre estas informações no período envolvido de 1995 até 2018.

Quanto à organização dos dados e informações é importante notar que os dados com relação ao preço do salário mínimo e o seu percentual de aumento, foram encontrados no DIEESE (Departamento Intersindical de Estatística e Estudos Socioeconômicos) e apresentados em forma de tabela nos anos de 1995 até 2018.

5 A mesma plataforma também disponibilizou os dados em relação à cesta básica com os valores por mês, tendo sido necessário realizar uma média de cada ano, desde 1995 até 2017, e em 2018 somente até o mês de julho. A mesma metodologia foi usada para obter os dados sobre o tempo despendido de trabalho para obtenção da cesta básica. Já os dados referentes ao número de cestas básicas adquiridas com um salário mínimo, foram encontrados de forma anual na plataforma.

6 No IBGE - Instituto Brasileiro de Geografia e Estatística, pelo IPCA - Índice Nacional de Preços ao Consumidor Amplo, foram adquiridos a porcentagem de aumento da inflação desde 1995 até 2018.

7 Com relação ao preço da terra no município de São Paulo, foram extraídos dados do índice FIPEZAP encontrados no site da Fundação Instituto de Pesquisas Econômicas FIPE, sendo a única plataforma que disponibiliza esses dados históricos, com os valores dos meses de junho e dezembro nos anos de 1995 a 2017. A tabela 1 apresenta a organização dos dados sobre o preço da terra, a evolução do salário mínimo e o tempo dispendido para obter a cesta básica no município de São Paulo, conforme as fontes já citadas.

8 Ainda, em relação aos dados, é importante notar que para ajustar as informações aos dados anuais foi necessário adotar médias, como em relação ao preço da terra, a partir das informações disponibilizado pela FIPE.

9 As informações apontam para a continuidade das crises. $O$ sistema capitalista, expandese de forma desordenada, impulsionando crises. Quando elas acontecem, o capital tem de encontrar novas formas de se reproduzir no espaço, aí surge a problemática em questão. Para se reinventar, o capital expande sua perversidade, ele cresce às custas do trabalhador, precarizando as relações de trabalho. Estas crises culminam na proliferação de um exército de reserva, arrocho salarial, perda de direitos trabalhistas, pobreza, falta de acesso à moradia de qualidade e infraestrutura urbana.

10 A cidade de São Paulo, mesmo sendo primordial para a produção e reprodução do capital no âmbito nacional, ainda apresenta inúmeras disparidades, como por exemplo, o acesso à terra, que nem sempre é compreendida a fundo. Ao mesmo tempo que o trabalhador perde a capacidade de compra da cesta básica, com a queda do salário mínimo ele perde também a capacidade de compra da terra nas áreas urbanas mais centrais da cidade.

11 Lembramos que estas áreas centrais são as áreas que mais concentram serviços e melhor se estruturam em termos de equipamentos urbanos coletivos. Deste modo, são estas áreas também as de maior preço, estando cada vez mais distantes do poder de compra do trabalhador de menor renda.

12 Ao mesmo tempo que o trabalhador perde a capacidade de compra com a queda do salário mínimo ele também é empurrado para as periferias desprovidas de serviços urbanos, levando ao processo de espoliação urbana (KOWARICK, 1984). 
13 Tratamos aqui, pois, do espaço que essa cidade (re) produz, em que se encontram implícitas e explícitas as relações sociais caracterizadas por um movimento intimamente ligado a fatores socioeconômicos e políticos.

Neste sentido, as informações sobre a evolução do salário mínimo, do poder de compra da cesta básica e a evolução do preço da terra, neste caso do município de São Paulo, possibilitam um panorama da qualidade de vida deste trabalhador, ou seja, são os rebatimentos das políticas econômicas na vida do trabalhador.

Os dados das fontes já citadas foram organizados sob a forma da Tabela 1, disposta a seguir, e a análise das evoluções de seus aspectos (salário mínimo, preço da terra e tempo de trabalho para obtenção desta cesta) foram contempladas nas discussões que se seguem.

Tabela 1: Município de São Paulo: Evolução do preço da terra, salário mínimo e tempo para a obtenção da cesta básica,1995-2018

\begin{tabular}{|c|c|c|c|c|}
\hline \multirow{2}{*}{ Ano } & \multirow{2}{*}{$\begin{array}{l}\text { Preço da Terra } \\
\text { (1) }\end{array}$} & \multirow{2}{*}{$\begin{array}{l}\text { Salário Mínimo } \\
(2)\end{array}$} & \multicolumn{2}{|c|}{$\begin{array}{l}\text { Tempo despendido para obtenção da Cesta Básica } \\
\text { (2) }\end{array}$} \\
\hline & & & Horas & Minutos \\
\hline 1995 & $\mathrm{R} \$ 21,46$ & $\mathrm{R} \$ 100,00$ & 223 & 33 \\
\hline 1996 & $\mathrm{R} \$ 26,47$ & $\mathrm{R} \$ 112,00$ & 193 & 30 \\
\hline 1997 & $\mathrm{R} \$ 28,45$ & $\mathrm{R} \$ 120,00$ & 164 & 23 \\
\hline 1998 & $\mathrm{R} \$ 29,43$ & $\mathrm{R} \$ 130,00$ & 180 & 36 \\
\hline 1999 & $\mathrm{R} \$ 30,51$ & $\mathrm{R} \$ 136,00$ & 175 & 36 \\
\hline 2000 & $\mathrm{R} \$ 36,82$ & $\mathrm{R} \$ 151,00$ & 172 & 18 \\
\hline 2001 & $\mathrm{R} \$ 34,6$ & $\mathrm{R} \$ 180,00$ & 161 & 38 \\
\hline 2002 & $\mathrm{R} \$ 38,2$ & $\mathrm{R} \$ 200,00$ & 155 & 25 \\
\hline 2003 & $\mathrm{R} \$ 41,10$ & $\mathrm{R} \$ 240,00$ & 161 & 17 \\
\hline 2004 & $\mathrm{R} \$ 40,71$ & $\mathrm{R} \$ 260,00$ & 149 & 28 \\
\hline 2005 & $\mathrm{R} \$ 47,28$ & $\mathrm{R} \$ 300,00$ & 137 & 22 \\
\hline 2006 & $\mathrm{R} \$ 53,30$ & $\mathrm{R} \$ 350,00$ & 115 & 22 \\
\hline 2007 & $\mathrm{R} \$ 57,85$ & $\mathrm{R} \$ 380,00$ & 114 & 27 \\
\hline 2008 & $\mathrm{R} \$ 69,22$ & $\mathrm{R} \$ 415,00$ & 126 & 33 \\
\hline 2009 & $\mathrm{R} \$ 83,46$ & $\mathrm{R} \$ 465,00$ & 109 & 38 \\
\hline 2010 & $\mathrm{R} \$ 102,37$ & $\mathrm{R} \$ 510,00$ & 107 & 21 \\
\hline
\end{tabular}




\begin{tabular}{|l|l|l|l|l|}
\hline $\begin{array}{l}2011 \\
(3)\end{array}$ & $\mathrm{R} \$ 130,82$ & $\mathrm{R} \$ 545,00$ & 108 & 29 \\
\hline 2012 & $\mathrm{R} \$ 153,98$ & $\mathrm{R} \$ 622,00$ & 94 & 30 \\
\hline 2013 & $\mathrm{R} \$ 175,79$ & $\mathrm{R} \$ 678,00$ & 106 & 29 \\
\hline 2014 & $\mathrm{R} \$ 192,45$ & $\mathrm{R} \$ 724,00$ & 104 & 38 \\
\hline 2015 & $\mathrm{R} \$ 199,7$ & $\mathrm{R} \$ 788,00$ & 118 & 37 \\
\hline 2016 & $\mathrm{R} \$ 200,69$ & $\mathrm{R} \$ 880,00$ & 113 & 32 \\
\hline 2017 & $\mathrm{R} \$ 202,87$ & $\mathrm{R} \$ 937,00$ & 101 & 31 \\
\hline 2018 & $\mathrm{R} \$ 205,54$ & $\mathrm{R} \$ 954,00$ & 101 & 35 \\
\hline
\end{tabular}

(1) FONTE: FIPE-FIPEZAP NOS ANOS DE 1995 A 2018

(2) FONTE: DIEESE NOS ANOS DE 1995 A 2018

(3) NO ANO DE 2011 HOUVE DOIS AUMENTOS: NA DATA DE 01/01/11 O SALÁRIO MÍNIMO FOI PARA R\$ $\mathbf{5 4 0 , 0 0}$ E EM 01/03/11 (DOIS MESES DEPOIS) ELE FOI PARA R $\mathbf{5 4 5 , 0 0}$ AUMENTANDO 0,93\%.

ORgANIZAÇÃO: PAULA VITORIA SANTOS E CAMILA PINHEIRO (2018)

Algumas questões foram surgindo para nortear a pesquisa: Quais políticas no período da redemocratização teriam afetado a evolução dos dados? Teria havido melhorias ou deterioração na qualidade de vida do trabalhador brasileiro após o país ter saído de uma profunda crise na década de 1980? Neste sentido, a questão principal deste trabalho é: A exploração constatada por Kowarick na década de 1980 tem se perpetuado no período da redemocratização?

Sob o aspecto científico, mais especificamente sob o aspecto político e social, é de grande importância e nosso objetivo averiguar quais são os rebatimentos da política brasileira nas condições básicas do trabalhador. Neste sentido, é que buscamos não somente dar continuidade ao importante trabalho de Lúcio Kowarick (1994) analisando o momento político atual, mas também, tecendo um comparativo dos governos com os do período da nova república.

\section{A perversidade no sistema capitalista}

No final do século XX e até o decorrer atual do século XXI, houve em amplas perspectivas, um acelerado aumento tecnológico, como também o desencadeamento de várias crises mundiais e nacionais, como por exemplo a de 2008. Crises essas que são inerentes ao sistema capitalista, que, acabam por, expandi-lo.

Expandir, no entanto, de forma a agregar espaços ao seu território e, também, de forma a expandir sua perversidade. Vamos analisar essa segunda forma de expansão, a perversidade.

Esta perversidade, que é tratada aqui manifesta-se estruturalmente no modo de (re) produção do trabalho, que precarizado, impulsiona o sistema capitalista. "A rigor, uma dimensão chave da crise estrutural e sistêmica do capital é a corrosão do trabalho" (CARVALHO, 2014 p. 228) 
21 O enfrentamento da crise econômica acaba por precarizar o trabalho, pois para determinado setor ser competitivo em via de voltar ao mercado, é quase um senso comum que ele deve diminuir os custos de produção para aumentar sua taxa de lucro. Essa diminuição provém, no entanto, do desequilíbrio da composição orgânica do capital.

Colocando o desemprego em perspectiva, se faz necessário discutir alguns pressupostos implícitos.

23 Em uma relação de trabalho, o proletariado vende a sua força de trabalho ou a sua capacidade produtiva ao capitalista, que a compra em forma de salário. Aqui a mercadoria é a força de trabalho e não o emprego. O capitalista necessita da força de trabalho para que haja a produção. Logo quando se diz que o empresário dá o emprego, a própria frase é falaz. Pois aquele que emprega não está dando nada, é somente uma relação de compra e venda.

24 Singer (1999) faz uma analogia em relação a teoria neoliberal muito difundida da oferta e demanda com o processo de precarização sob o ponto de vista do salário.

25 Na economia, se a demanda excede a oferta, há uma ascensão dos preços que resulta em inflação, logo o Estado toma medidas para equilibrar a inflação e regular os preços, por isso é necessário que haja mais oferta do que demanda, para que a concorrência se estabeleça entre o ofertante e não entre os consumidores.

Como o emprego é tido como uma relação de compra e venda de força de trabalho, o desemprego seria um efeito funcional desta estabilização da economia entre a oferta (trabalhador, dono da força de trabalho) e a demanda (capitalista).

As políticas fiscais e monetárias têm em vista impedir que a economia se "aqueça" em demasia, o que na prática implica manter uma generosa margem de sobreoferta de força de trabalho. Neste sentido, o desemprego não é um "mal", mas um efeito funcional de políticas de estabilização exitosas. (SINGER, 1999 p.13)

É necessário que isto aconteça para manter cada vez mais baixos os salários. Portanto, o exército de reserva ${ }^{1}$ evita que os salários subam empenhando um papel estabilizador.

Inicia-se nesse ponto a precarização, pois com o desemprego estrutural e com o avanço da crise econômica cria-se um amplo exército de reserva que acaba por ser impossibilitado de usufruir de direitos trabalhistas garantidos por lei, através de inúmeras conquistas de classe ao longo da história.

29 Quem deveria assumir um papel regulador entre os interesses do capital e o da sociedade seria o Estado. Porém, este trabalha para manter a ordem estabelecida, a dominância da burguesia e seus privilégios, sendo este um ponto de contradição do sistema social, já que é o Estado que regula e arbitra as discussões salariais para que não haja uma crise generalizada e a concentração de renda fique exorbitante.

Este ponto de contradição faz com que em determinadas conjunturas o Estado aja de diferentes maneiras, de forma a conciliar as necessidades de acumulação do capital com os imperativos da reprodução da força de trabalho, ou seja, conforme o equilíbrio das forças sociais em presença. Em determinadas conjunturas, são as necessidades de acumulação que recebem prioridade, em outras, são os imperativos da reprodução que são favorecidos, tornando sempre este jogo de interesses muito complexo. o que caracteriza o Estado em si.

31 Os rumos que o Estado no Brasil vem tomando desde a redemocratização seguem esta mesma lógica. 

obtenção da mais-valia e a exploração do trabalho, resulta em concentração de renda e, também em diminuição da capacidade de consumo por parte do trabalhador afetando a dinâmica econômica. (DIT) agravada cada vez mais por crises cíclicas, assistenciadas pela corrosão de direitos, precariza as relações de trabalho e a obtenção de renda do trabalhador de forma que este não consegue ter o acesso básico ao mínimo necessário para viver.

Outro aspecto de extrema relevância e que seria uma questão chave não só para o entendimento da exclusão social deixada pela forma como o capital se reproduz no espaço, mas para entender de onde derivam todos esses aspectos de fragilidades das relações sociais seria o acesso à terra.

As condições de moradia as quais o trabalhador possui acesso, não são somente resultado de seu poder aquisitivo, mas também de um conjunto de políticas públicas urbanas relacionadas a melhoria dos equipamentos urbanos coletivos. Em outras palavras a qualidade de vida não depende só do fato da qualidade da sua habitação propriamente dita, mas do acesso aos equipamentos coletivos urbanos como ruas asfaltadas, calçadas, escolas, creches, postos de saúde, saneamento básico, transporte e áreas de lazer.

36 Para entendermos o processo de acessibilidade do trabalhador à terra é necessária uma visão mais ampla sobre outros aspectos da economia, não sendo possível tratá-la de maneira isolada. Dada a importância deste assunto dentro deste trabalho, discutiremos alguns conceitos a fim de uma melhor elucidação dos processos de habitação na metrópole paulista e suas dinâmicas envolvidas. Deste modo se discutirá como se dão a segregação sócio espacial, as políticas públicas urbanas e a autoconstrução.

37 A medida em que o trabalhador com uma menor renda não possui condições de se manter em um local privilegiado, dotado de uma boa infraestrutura e oferta de serviços públicos, ele irá se instalar nas regiões periféricas. Assim, o "espaço urbano torna-se um meio e um poder nas mãos da classe dominante" [...] (CARLOS, 2017, p.35). Esta classe dominante se beneficia da valorização das áreas mais centrais ou onde são aplicados investimentos públicos. Os governantes, por sua vez, por meio das políticas públicas urbanas e habitacionais orientam estes fluxos de investimentos e de valorização (CARLOS, 2017). Assim, esta política urbana "direciona e regulariza os fluxos centralizando, valorizando e desvalorizando os lugares da vida, e aprofundando as desigualdades" (CARLOS, 2017, p. 35).

A falta ou precarização das condições socialmente necessárias, que os serviços de caráter coletivo deveriam suprir a toda a população, é denominada por Kowarick (1979) de espoliação urbana. Assim, além da superexploração do trabalho, a população tem a sua qualidade de vida comprometida por falta de investimento público em moradia, água, luz e transporte (KOWARICK, 1979).

Privar o trabalhador de condições de vivência de qualidade na cidade, lhe tirando o direito de acesso à bens de consumo coletivo também é uma forma de segregar. "A segregação - como forma da desigualdade espaço-temporal - realiza-se como a negação do urbano e da vida urbana através da separação dos lugares da vida enquanto elementos autônomos" (CARLOS, 2017, p.35). 

benfeitorias urbanas, priorizaram as regiões centrais, declarando a administração de caráter elitista do período. Em um âmbito local os investimentos da prefeitura na infraestrutura habitacional durante a ditadura não ocorreram de forma distributiva entre as periferias e as regiões centrais. As últimas teriam sido privilegiadas (MARQUES E BICHIR, 2001).

Segundo Kowarick (1979) as questões da qualidade habitacional não envolvem somente o preço da terra determinado pelo mercado imobiliário, mas também envolvem os investimentos públicos fornecidos que agregam valor ao preço final da moradia. Decorrente desse fato as políticas públicas podem causar uma segregação ainda maior no espaço urbano, uma vez que é fator fundamental no preço da terra.

O crescimento do padrão periférico como denominado por KOWARICK (1994), é dado principalmente pela autoconstrução de moradias, em que os trabalhadores a fim de se livrarem do peso de um gasto como o aluguel empenham esforços para concretizar seu desejo por uma moradia própria, mesmo que isso comprometa sua saúde e energia. Neste contexto, é importante lembrar que muitos trabalhadores utilizam o seu tempo livre de trabalho para outros expedientes ligados à construção de sua moradia pela via do mutirão, ou ainda, buscam complementar sua renda com mais trabalho de forma a possibilitar arcar com os gastos da obra.

Diante do fluxo econômico e intensificação industrial em São Paulo por volta de 1950, os investimentos em serviços públicos ficaram voltados as regiões centrais, valorizando o espaço e, consequentemente aumentando o valor da terra. Ao mesmo tempo, à medida que a população aumentava com os fluxos migratórios em busca de trabalho na metrópole, eram nas regiões mais afastadas que estes migrantes se assentavam. Os centros bem servidos de equipamentos coletivos eram caros e estes trabalhadores não possuíam recursos para aí se fixar. Diante dessa situação é que se inicia a consolidação da periferia, vista como uma única solução para atender a demanda populacional.

Hoje as periferias urbanas do Município de São Paulo já alcançam os limites do município e se chocam com as áreas urbanas de municípios vizinhos em um movimento de conurbação cada vez mais amplo.

Este crescimento periférico teve origem no período de crise da habitação oriunda da ditadura militar, apresentando uma lógica que acabou agravando ainda mais as desigualdades que já eram presentes nos períodos anteriores (KOWARICK,1994). Estes fatos são demonstrados claramente quando são analisados os dados da época na obra do autor. A queda significativa do salário mínimo combinado ao aumento do preço da terra foi determinante para toda a extensão periférica e dos cortiços entre a década de 1970 e 1980.

A priorização de investimentos, no mesmo período, foi em grandes projetos de financiamento e obras de construção de moradia como o BNH (Banco Nacional de Habitação) e a Companhia Pública Municipal de Habitação em áreas periféricas do município, que comprometiam um alto valor para o investimento e aumentava o lucro de construtoras. Segundo Kowarick (1994) os programas facilitaram mais a especulação imobiliária, do que possibilitou famílias de baixa renda de obter o sonho da casa própria. o agravamento da perda do poder aquisitivo e os investimentos públicos em Decorrente dessa precarização e da desigualdade social evidente é que surgem as lutas urbanas, que apesar de reprimidas pelo regime, foram grandes movimentos de 
reivindicação do acesso à serviços básicos de água, esgoto, transporte, creches, entre outros.

No período ora analisado conseguimos entender como a consolidação da periferia na metrópole paulista envolve um problema estrutural, já que a desigualdade de acesso à terra não se resolve somente com programas habitacionais.

Segundo MARICATO (1996) o Estado acaba desenvolvendo uma estrutura de mercado imobiliário capitalista para uma minoria, que possui acesso à uma moradia privilegiada, enquanto que para a maioria só lhe resta as opções em lugares afastados de todas as metrópoles, desprovidos de urbanização, como as favelas e cortiços.

Assim, as favelas têm crescido rapidamente em população nos últimos anos, necessitando, por sua vez, formas diferentes de tratamento. Assim, neste quadro duradouro de desigualdade as favelas brasileiras devem ser vistas como "expressões estruturais do processo desigual que caracteriza a urbanização da sociedade brasileira" (BARBOSA, 2017, p.180).

51 Essas condições de moradia não são relacionadas apenas ao baixo poder aquisitivo da população, ou seja, o morador da favela não revela somente possuir baixa renda, mas, também se insere em um contexto com muitos problemas como a vulnerabilidade à violência urbana, a perda da saúde devido diversos impactos ambientais, visto as péssimas condições de acesso à rede de esgoto, saneamento básico e coleta de lixo.

É a ilegalidade ou clandestinidade em face de um ordenamento jurídicoinstitucional, que ao desconhecer a realidade sócio econômica da maioria, nega o acesso à benefícios básicos para a vida na cidade. Não se trata apenas de perversidade inconsciente de tecnocratas bem-intencionados. Trata-se de um processo socioeconômico e político que produz uma concepção de ordem estreita e excludente, e ao fazê-lo, decreta uma vasta concepção de subcidadania.

53 Para compreender a evolução do preço da terra, no período da redemocratização, no município de São Paulo, voltamos a analisar a Tabela 1, disponibilizada na introdução deste trabalho.

Ao observar a tabela, percebe-se que entre 1995 e 1996 houve um aumento de $23 \%$ no preço da terra, enquanto que o salário mínimo foi contemplado somente com $12 \%$ de aumento. No curto período entre 1996 a 1998 o preço da terra cresceu menos do que o salário mínimo, mas estes valores não foram significativos. Entre 1999 e 2000, no entanto, o preço da terra aumenta $20 \%$ enquanto que no mesmo período o salário mínimo aumenta $11 \%$. Mas, em 2003 é a vez do salário mínimo apresentar maior valorização, com $20 \%$, enquanto que o preço da terra em 2004 só alcança cerca de $7 \%$. Nos anos que se seguiram, no entanto, especialmente entre 2008 e 2013 o preço da terra volta a crescer mais do que o salário mínimo, afastando ainda mais o trabalhador da conquista da casa própria. No entanto, este crescimento não se mantém constante, apontando para uma queda nos últimos anos. É importante que compreendamos estas oscilações relacionadas às políticas econômicas de cada período.

No que diz respeito às tentativas dos governos de solucionar os problemas relacionados ao acesso à terra e, consequentemente à moradia, é necessário levar em conta a situação política e econômica em um âmbito nacional e até mesmo global. Parte-se da hipótese de que, após a crise da década de 1980, com mudanças na década de 1990 como a adoção do plano real equiparando com o valor do dólar, as condições financeiras que propiciassem à população o acesso à moradia também estariam mais acessíveis. 

imobiliária com o surgimento de uma onda de financiamentos inseguros que levou à inadimplência, falindo diversas empresas envolvidas nos empréstimos imobiliários, gerando uma crise imensa no país. uma baixa, como nossa principal fonte na economia, os reflexos não seriam nada além do esperado.

58 A economia brasileira já na metade da década de 1990, estava aparentemente caminhando para uma situação mais estabilizada e, posteriormente com a entrada do governo Lula dando continuidade no controle da inflação, junto com suas medidas de acessibilidade à linhas de crédito, a população começou a consumir mais.

Em 2007 foi paga a dívida externa, e diante desse cenário o setor imobiliário aproveitou para aumentar os preços dos imóveis de forma desenfreada, já que a possibilidade de financiamento e a economia aparentemente estabilizada daria condições para que os trabalhadores pudessem adquirir sua casa própria. Paradoxalmente, o valor da terra entre 2008 e 2013 apresentou um grande aumento, chegando em até $27,8 \%$ no ano de 2011.

Apesar do aumento do salário mínimo, não havia possibilidade de acompanhar a escalada do preço da terra. Deste modo, com essa supervalorização e o poder de consumo relativamente estagnados, a demanda diminui, o que explica a estabilização dos preços a partir do ano de 2015.

61 Podemos perceber, durante os primeiros anos na tabela, como o preço da terra continuou aumentando, visto que o salário mínimo não acompanhava esse crescimento.

No governo de FHC houve uma alta taxa de desemprego decorrente do plano de contenção da inflação no período anterior. 0 preço da terra nos seus primeiros anos de governo aumentava gradativamente acompanhando de certa forma o poder de consumo da população, apesar de ainda se manterem altos. A preocupação com a habitação no governo de FHC foi pautada em um plano com a criação do Estatuto da Cidade que acabou se tornando um recurso bastante utilizado pelo setor privado que se beneficiou do programa para captar recursos do FGTS objetivando a produção de moradias prontas. Apesar de ser um programa de grande escala, e comprometer quase metade do orçamento destinado à habitação, não obteve sucesso em melhorar a situação do déficit habitacional, além disso, pouco contribuiu para a criação de empregos no país, como um problema ainda vigente.

63 Já no governo Lula, se desenvolveu o programa habitacional Minha Casa Minha Vida, administrado pelo Ministério das Cidades. Este programa consiste em construir unidades habitacionais sendo vendidas posteriormente às famílias, que poderiam obter benefícios e facilidade para financiamento, sendo proporcional as rendas das famílias, que se dividiam em 4 faixas de renda como determinado pelo programa. O programa Minha Casa Minha Vida atendeu muitas expectativas se sobressaindo como maior programa habitacional do país. Entretanto, ainda devemos destacar que as unidades habitacionais se localizavam em espaços desvalorizados de baixa infraestrutura, com pouco acesso as redes de transportes e serviços públicos.

64 Em contrapartida, a partir da análise dos dados dos últimos anos é possível inferir que se estabelecem algumas condições para aquisição da casa própria. De 2015 até 2018 percebemos uma certa estagnação no valor da terra, chegando à um mínimo aumento 
de 0,49 em 2016, e apesar do aumento quase insignificante do salário mínimo, ele consegue se manter superior ao aumento do valor da terra, o que poderia facilitar na conquista da casa própria.

\section{As condições de vida do trabalhador no período da redemocratização}

Em relação ao salário mínimo, nos primeiros seis anos de análise não houve um crescimento muito significativo, principalmente se levarmos em conta a inflação.

Segundo o Instituto Brasileiro de Geografia e Estatística (IBGE) no ano de 1996 a inflação cresceu $16,1 \%$ enquanto o salário mínimo, segundo o Departamento Intersindical de Estatística e Estudos Socioeconômicos (DIEESE), cresceu 12\% no mesmo período. Ou seja, o salário ficou abaixo da inflação.

O Plano Real ainda estava em período de estabilização, logo após 1996 o índice da inflação foi diminuindo e o salário mínimo aumentando timidamente pouco acima ou abaixo da inflação, como por exemplo, em 1997 que a inflação aumentou 6,97\% e o salário mínimo 7,14\% e em 1999 em que a inflação teve alta de 4,86\% enquanto o salário mínimo cresceu 4,62\% ficando abaixo da inflação. Isto aponta que o salário mínimo não apresentou ganhos significativos, por conta da inflação contida.

Segundo o DIEESE, em 1998 o preço da cesta básica cresceu 9\%, diminuindo o poder de compra do trabalhador em $0,81 \%$. No mesmo ano notou-se um aumento do número de horas trabalhadas para obter a cesta básica que foi de 164 horas e 23 minutos para 180 horas e 36 minutos aumentando 9,82\% o tempo de trabalho, embora ele viesse diminuindo nos anos anteriores.

Isso mostra a instabilidade que ocorria no governo do Fernando Henrique Cardoso (FHC) com um cenário nada favorável para a população pobre que já vinha sofrendo desde a década de 1980, chamada por KOWARICK (1994) de a década mais que perdida.

Durante o governo Lula entre 2002 e 2010, houve uma melhora no quadro de aumento do salário mínimo. É sempre interessante lembrar que este governo elegeu-se prometendo governar para os trabalhadores e para as camadas mais pobres da população.

71 Podemos observar essa preocupação com a expansão de programas sociais como o Bolsa Família, Minha Casa Minha Vida, ProUni etc. e também com o aumento do salário mínimo que mais que dobrou durante o período, indo de $\mathrm{R} \$ 200,00$ para $\mathrm{R} \$ 531,00$, um aumento de $155 \%$.

É importante notar, que apesar de ter apresentado entre 2002 e 2003 um aumento de $20 \%$ no salário mínimo, este crescimento não foi capaz de produzir alterações significativas, principalmente no que diz respeito ao acesso à terra.

Em um governo em que a prioridade seria o bem-estar do trabalhador, já que a gestão do Partido dos Trabalhadores prevaleceu durante a maior parte deste período, o crescimento do salário mínimo não passar de $20 \%$ ao ano, é no mínimo um indicativo preocupante em que se questiona a serviço de quem o governo trabalhou ao longo dos anos, já que se manteve a ordem pré-estabelecida dos interesses do capital.

4 No ano de 2003, o número de horas trabalhadas voltou a aumentar em 3,81\% (em relação à 2002). Em 2002 se trabalhava 155 horas e 25 minutos para se obter uma cesta 
básica, e no ano seguinte 161 horas e 17 minutos. Portanto, nota-se que este ano marcou uma quebra na queda do número de horas trabalhadas que vinha desde 1998. Depois de 2003, volta a se registrar quedas até 2007, seguida de pequenas oscilações.

No ano de 2006 a inflação estava em baixa com um índice de 4,2\% ao mesmo tempo em que o salário mínimo tinha obtido uma valorização de 16,67\% (valia $\mathrm{R} \$ 300,00$ e passando a valer $\mathrm{R} \$ 350,00$ ) em relação ao ano anterior. Este foi um ano significativo, tendo em vista que o salário aumentou $16,67 \%$ o preço da cesta básica diminuiu $0,58 \%$. Isto resultou no maior aumento do poder de compra para o trabalhador que vivia com o salário mínimo em todo o período analisado, ou seja, foi o melhor índice ao longo desses 23 anos.

No decorrer deste período de governo a economia esteve favorável, a inflação mantevese baixa e o salário mínimo em crescente. Percebe-se duas fases da gestão do Partido dos Trabalhadores no governo. Dentre esses 8 anos de governo Lula houve significativas conquistas para a classe trabalhadora, em relação aos demais períodos governamentais que $o$ antecederam e o sucederam.

77 O governo de Dilma Rousseff não manteve os mesmos índices de crescimento. 0 salário mínimo paulatinamente foi diminuindo enquanto a inflação ia se dilatando. Houve, também, aumento das horas trabalhadas para se obter a cesta básica.

78 Este quadro foi piorando em vista da crise econômica que se instalava no país, agravada por fatores externos e internos. Para entender um pouco melhor deste contexto, faz-se necessário uma retomada sobre as medidas econômicas adotadas.

79 No decorrer da primeira década do século XXI, a economia nacional obteve significativas taxas de crescimento comparadas com a década final do século XX. Entretanto, este contexto positivo da economia nacional foi favorecido pelo contexto mundial da economia, com maior liquidez de capital e alta no preço das commodities.

80 Perondi (2017) aponta que as políticas econômicas aplicadas pelo Partido dos Trabalhadores (PT) nesse período de governo, de uma forma geral, mantiveram as bases neoliberais implantadas no Plano Real, notadamente o tripé macro-econômico (superávit primário, controle do câmbio e metas de inflação determinadas por elevadas taxas de juros). Neste período, houve um grande aumento da arrecadação que proporcionou maiores investimentos do Estado em iniciativas de distribuição de renda direcionadas ao combate da pobreza extrema, especialmente o Programa Bolsa Família, como também proporcionou uma oferta maior do crédito ao consumo por parte dos bancos estatais. Contudo, para a implementação desse tripé, o pressuposto de tais medidas gerou lucros sem precedentes ao sistema financeiro, e drenou parte importante do orçamento do Estado para serviços da dívida pública.

81 Em 2008 a crise mundial assolou grandes potencias como os Estado Unidos e os países da União Européia, em 2009 ela chegou no Brasil desacelerando a economia (PERONDI, 2017). Houve uma desaceleração do $\mathrm{PIB}^{2}$ nacional de $0,3 \%$ levando o governo a tomar medidas anticíclicas que culminaram em uma recuperação de 7,5\% em 2010. 0 que levou a se pensar que o país não sofreria com a crise.

82 No entanto, a perda da movimentação da economia com a alta nos preços das commodities e a desaceleração do comércio com a China resultaram na desaceleração da economia em 2012 e na recessão em 2015. 
Segundo Singer (2015) em 2012 o governo Dilma teria adotado medidas neodesenvolvimentistas, chamada de nova matriz econômica ou ensaio desenvolvimentista.

A iniciativa estava direcionada principalmente a salvar os lucros industriais dos efeitos da crise. E o fazia com a diminuição dos custos trabalhistas e transferências diretas e indiretas de recursos do Estado para fomentar os lucros dos capitais internacionais e promover a internacionalização de setores da burguesia interna. (PERONDI, 2017, p.607)

Contudo, não foi possível agradar a burguesia e os trabalhadores. Em 2015 houve um corte orçamentário, principalmente nas pastas que eram responsáveis por serviços públicos. Também houve restrições dos direitos trabalhistas como o seguro desemprego, abono salarial, pensão por morte e auxílio para trabalhadores doentes. Foram estipuladas regras e tempos de trabalho mais longos para o acesso aos benefícios. Como visto na tabela, houve um aumento do número de horas de trabalho a partir de 2015, em cerca de $13 \%$.

Esse quadro tende a piorar nos dias atuais com a reforma trabalhista, que propõe a ampliação do período de trabalho parcial (passa de 25 para 30 horas).

As contradições do governo de hora atender a massa trabalhadora e hora atender os interesses do capital, o que de fato configura o Estado, causou descontentamento de ambos os lados. Instaurando inúmeras greves no país, principalmente a partir de 2013, e instabilidade nos investimentos econômicos estrangeiros, além do fato da grande crise política devido as denúncias de corrupção na Lava-Jato que acabaram culminando no impeachment da presidente em 2016 e a posse do seu vice presidente Michel Temer.

Com a pressão das classes dominantes, no final do governo Dilma e principalmente durante o governo de Michel Temer implantou-se o ajuste fiscal, visando a retirada de direitos trabalhistas e a contração de políticas sociais que consistia em:

1)Ajuste fiscal para frear o crescimento da dívida pública e da inflação; 2) redução dos custos trabalhistas e aumento da produtividade do trabalho, através do aumento da flexibilidade nas contratações/demissões, generalização da terceirização, incremento tecnológico; 3) redução do fundo social, eliminando obrigações orçamentárias a políticas sociais e desindexação dos benefícios da reforma da Previdência; 4) favorecer novos negócios e investimentos, através de privatizações e concessões (pré-sal, portos, aeroportos, rodovias, companhias de energia e saneamento, entre outros); 5) maior abertura comercial e busca de acordos preferencialmente com Estados Unidos e União Europeia em detrimento do Mercosul. (PERONDI, 2017, p.611)

Aqui podemos inferir que a intenção dessas medidas é de caráter neoliberal, em que se visa a precarização do trabalho e, consequentemente deteriora a vida do trabalhador.

Outra informação importante relacionada ao período em análise é sobre a taxa oficial de desemprego, que segundo o IBGE, dobrou entre 2014 e 2016 afligindo mais de 14 milhões de trabalhadores. Adicione-se a essa conta também outros 23 milhões de subocupados, tendo em vista que os ganhos médios dos trabalhadores também foram reduzidos nas negociações salariais (para as categorias que têm acordo coletivo).

Segundo o DIEESE (2016), 39\% destas categorias tiveram reajuste abaixo da inflação anual, sem discutir que muitos reajustes foram parcelados. Outro dado significativo consiste nas novas contratações que pagam salários $21 \%$ mais baixos do que os recebidos pelos demitidos na mesma ocupação. Já é realidade no Brasil a precarização 
do trabalho como efeito da crise, consistindo entre outras coisas, no rebaixamento de salário e na ascensão de um exército de reserva.

91 Perondi (2017) aponta que a desregularização das relações de trabalho já se desenvolveu bastante durante o governo do Fernando Henrique Cardoso (FHC) por conta das mudanças na legislação trabalhista. No entanto, mesmo nos governos petistas, sobretudo nos governos de Dilma Rousseff, não houve uma grande reversão nesse padrão, embora seja impossível negar os grandes avanços sociais no governo anterior, pois o objetivo real era conseguir conciliar os interesses dos capitalistas e da classe trabalhadora. No entanto, uma exorbitante deterioração nessas relações de trabalho respaldadas por lei foi um marco da história brasileira com a reforma trabalhista no governo de Temer, firmando o golpe no trabalhador.

Entre os anos de 2016 e 2018, é notável os retrocessos sociais deixados pelo governo Temer. Podemos observar a característica liberal, em que claramente priorizou os aspectos econômicos e financeiros, pelo controle da inflação em 3,6 em 2018, em detrimento da equiparação da inflação com o salário mínimo, tendo seu reajuste em apenas $1,81 \%$ em 2018, o menor reajuste dentre todos os anos analisados.

\section{Considerações Finais}

93 É preocupante a disseminação no ideário popular de que tais medidas de precarização do trabalho, são importantes e necessárias para resgatar o rumo da economia e gerar novos empregos. Como já vimos, a manutenção do emprego é utilizada como argumento para a retirada de direitos historicamente adquiridos e avanço do capital e dos seus meios de acumulação em um novo movimento de retirada da mais-valia.

As relações de trabalho compõem parte fundamental do sistema capitalista, que se utiliza dessas relações para sua manutenção. Geralmente este sistema utiliza-se de crises, que lhe são inerentes, e do desemprego, como sua consequência, para implantar medidas de austeridade econômica que acabam por precarizar as relações de trabalho e estabelecer novos patamares para que o capital obtenha mais-valia.

A qualidade de vida se atrela as relações de trabalho. Pois é por meio da venda da força de trabalho, que o trabalhador e sua família obtém acesso aos meios para sua subsistência.

O salário mínimo é imprescindível quando se trata de relações de trabalho e de consumo básico. Visto que, a sua porcentagem de aumento e o seu valor influenciam diretamente na compra da cesta básica, e no quanto o trabalhador tem que trabalhar para adquiri-la, além de estar diretamente ligado ao acesso à moradia em áreas com infraestrutura urbanas.

No decorrer deste período de redemocratização os governos atuaram de maneiras distintas em relação a políticas públicas voltadas a classe trabalhadora, ao controle da inflação e do aumento do salário mínimo.

Durante os primeiros anos da redemocratização, a economia estava instável, com isso notava-se uma alternância nos preços do salário e inflação. No governo Lula houve uma relativa melhoria em comparação a outros períodos, foi nesse contexto em que se investiu mais em programas sociais com políticas voltadas a massa trabalhadora e a população pobre. Vale ressaltar que mesmo com tal melhora, essa não foi suficiente para que problemas como do acesso à terra e à moradia fossem resolvidos. Os índices de 
crescimento não foram mantidos no governo Dilma e a crise econômica, bem como os escândalos de corrupção levaram à crise política que culminou com seu impeachment.

o governo Temer, por sua vez, apresentou a retomada de medidas que concorrem para a precarização do trabalho, abrindo um terreno de incertezas onde se elegeu Jair Bolsonaro (PSL) que apresenta reformas que apontam o acirramento da precarização do trabalho. Resta acompanhar este processo e reforçar a importância da manutenção dos institutos e órgãos de pesquisa, como o Dieese para que se possa continuar avaliando os próximos períodos.

Sendo a cidade mais populosa do Brasil, entendemos que o problema da moradia em São Paulo é estrutural, fatores como o não acompanhamento do salário mínimo com o preço da terra, e o boom imobiliário no país logo após a crise econômica nos Estados Unidos, com grandes percentuais de aumento no valor da terra chegando até o ano de 2014, contribuíram de forma significativa para a impossibilidade de milhões de trabalhadores adquirirem sua casa própria. Junto a isso a falta de comprometimento dos governos em trazer melhoria em equipamentos urbanos para as periferias também coloca em risco a qualidade de vida do trabalhador. Esses fatores nos levam a compreender a espoliação urbana como parte de uma exclusão social, que compromete grande parte da qualidade de vida da população.

Embora o trabalhador tenha obtido ganhos no salário mínimo que quase chegou a ser 10 vezes maior do que há 23 anos, observa-se que este trabalhador ainda não tem acesso à terra e a luta para sua obtenção perpetua uma situação de exploração da força de trabalho em um movimento cíclico.

\section{BIBLIOGRAFIA}

BARBOSA, Jorge Luiz. As favelas na reconfiguração territorial da justiça social e dos direitos à cidade. In: CARLOS, A. F. A.; ALVES, G. A.; PÁDUA, R. F. Justiça Espacial e o Direito à Cidade. São Paulo: Ed. Contexto, 2017 p. 179-187

CARLOS, A.F.A. A privação do urbano e o "direito à cidade" em Henri Lefebvre.In CARLOS, A.F.A; ALVES, G.A e PÁDUA, R.F. Justiça espacial e o direito àcidade. São Paulo: Contexto, 2017 p. 33-63

CARVALHO, A. M. P. A precarização estrutural do trabalho na civilização do capital em crise: o precariado como enigma contemporâneo. In Revista de políticas públicas. Revista online. Ed. Especial, v.18 São Luiz; EDUFMA 2014 p. 225-239 Disponível em:

http://www.periodicoseletronicos.ufma.br/index.php/rppublica/issue/view/200/showTo Acessado em: 12/09/18

DIEESE. Departamento intersindical de estatística e estudos socioeconômicos. Balanço das negociações dos reajustes salariais do $1^{\circ}$ semestre de 2016. Estudos e Pesquisas, São Paulo, n.81, set.2016. Disponível em: https://www.dieese.org.br/balancodosreajustes/2016/ estPesq81balancoReajustes1s emestre2016.pdf Acessado em: 01/10/2018 
DIEESE. Departamento intersindical de estatística e estudos socioeconômicos. Banco de dados. Cesta básica de alimentos. São Paulo. 1995-2018 Disponível em:https://www.dieese.org.br/ cesta/Acessado em: 03/08/18

DIEESE. Departamento intersindical de estatística e estudos socioeconômicos. Banco de dados. Cesta básica de alimentos, tempo de trabalho. São Paulo 1995-2018 Disponível em: https:// www.dieese.org.br/cesta/Acessado em: 03/08/18

DIEESE. Departamento intersindical de estatística e estudos socioeconômicos. Nota técnica. Quantidade de cestas básicas adquiridas com um salário mínimo: São Paulo - 1995-2018. Disponível em: https://www.dieese.org.br/notatecnica/2018/notaTec188SalarioMinimo.html Acessado em: 15/08/18

DIEESE. Departamento intersindical de estatística e estudos socioeconômicos. Pesquisa nacional da Cesta Básica de Alimentos, salário mínimo nominal e necessário 1995-2018 Disponível em:https://www.dieese.org.br/analisecestabasica/salarioMinimo.html Acessado em: 01/08/18

FIPE. Fundação Instituto de Pesquisas Econômicas. Índice Fipezap histórico de preços de Imóveis anunciados. 1995-2015 Disponível em:http://www.fipe.org.br/pt- br/indices/fipezap/ \#fipezap-historico Acessado em: 20/08/18

FIPE. Fundação Instituto de Pesquisas Econômicas. Índice Fipezap de preços de Imóveis anunciados. 2016-2018 Disponível em: http://www.fipe.org.br/pt- br/indices/fipezap/\#fipezaphistoricoAcessado em: $20 / 08 / 18$

FREHSE, Fraya. Potencialidades do método regressivo-progressivo: pensar a cidade, pensar a história. Tempo social; Rev. Sociol. USP, S.Paulo, 13(2): 169-184, novembro de 2001

IBGE Instituto Brasileiro de Geografia e Estatística. Domicílios particulares em aglomerados subnormais, por localização, 2010 São Paulo Disponível em: https://www.ibge.gov.br/ estatisticas-novoportal/sociais/populacao/9662-censo-demografico-010.html? edicao $=9678 \& \mathrm{t}=$ destaques Acessado em: 08/08/18

IBGE Instituto Brasileiro de Geografia e Estatística. PME. Pesquisa Mensal de Empregos 2014-2016. Disponível em: https://www.ibge.gov.br/estatisticas- novoportal/sociais/trabalho/ 9180-pesquisa-mensal-deemprego.html?=\&t=destaques Acessado em: 01/10/2018

IBGE Instituto Brasileiro de Geografia e Estatística. IPCA. Índice Nacional de Preços ao Consumidor Amplo. 1995-2018 Disponível em:https://www.ibge.gov.br/estatisticasnovoportal/economicas/precos-e-custos/9256-indice-nacional-de-precos-ao- consumidoramplo.html?=\&t=o-que-eAcessado em: 15/08/18

KOWARICK, L. Autoconstrução de moradias e espoliação urbana. In KOWARICK, L. A espoliação urbana. Rio de Janeiro: Paz e terra, 1979 p. 55-75

KOWARICK, L. CAMPANÁRIO, M. São Paulo, metrópole do desenvolvimento industrializado: do milagre a crise econômica. In KOWARICK, L. e CAMPANÁRIO, M. As lutas sociais e a cidade. $2^{\circ}$ Ed. São Paulo: Paz e terra, 1994 p. 53-72

KOWARICK, L. BONDUKI, N. Espaço urbano e espaço político: do populismo a redemocratização.In KOWARICK, L. e CAMPANÁRIO, M. As lutas sociais e a cidade. $2^{\circ}$ Ed. São Paulo: Paz e terra, 1994 p. $147-177$

MARICATO, E. Urbanismo na periferia do capitalismo: Desenvolvimento da desigualdade e contravenção sistemática. In MARICATO, E. Metrópole na periferia do capitalismo: ilegalidade desigualdade e violência.São Paulo: Hucitec, 1996 p. 21-49 
MARQUES. E; BICHIR.R. Estado e espaço urbano: Revisitando criticamente as explicações sobre as políticas urbanas. Revista de Sociologia e Política. Curitiba, n. 16, p. 9-29, jun. 2001

PERONDI, E. Crise econômica e instabilidade política: cenários da ofensiva do capital contra o trabalho no Brasil. In Revista de políticas públicas. Revista online. Ed.

Especial, v.21 n.2 São Luiz; EDUFMA 2017 p. 603-622 Disponível em: http:// www.periodicoseletronicos.ufma.br/index.php/rppublica/article/view/8236 Acessado em: 27/09/18

SINGER, A. Cutucando onças com varas curtas: o ensaio desenvolvimentista no primeiro mandato de Dilma Rousseff (2011-2014). Novos Estudos Cebrap, São Paulo, 2015 n. 102, p. 39-67.

SINGER, P. Globalização e desemprego: diagnóstico e alternativas. 3. ed. São Paulo: Contexto, 1999.

\section{NOTAS}

1. Exército de reserva corresponde à força de trabalho que excede as necessidades da produção devido ao desemprego estrutural, ou seja, os desempregados que buscam voltar a vender sua força de trabalho e receber salário. Ressaltando que sob forma de um emprego formal 2. PIB: Produto Interno Bruto, representa a soma, em valores monetários, de todos os bens e serviços finais produzidos numa determinada região, durante um determinado período.

\section{RESUMOS}

Este trabalho busca analisar os rebatimentos das políticas econômicas na vida do trabalhador paulistano, tomando como metodologia as análises de Lúcio Kowarick e Milton A. Campanário (1994) sobre as condições de vida do trabalhador no período que envolve a década mais do que perdida (1980). Assim como no trabalho de Kowarick e Campanário (1984), este trabalho procurou reconhecer nas informações sobre a evolução do salário mínimo, poder de compra da cesta básica, número de horas trabalhadas para obtenção da mesma e da evolução do preço da terra entre 1995 e 2018, os rebatimentos das políticas trabalhistas desenvolvidas no mesmo período. Neste sentido, este artigo procura avaliar como foi a qualidade de vida do trabalhador no período de redemocratização, mais especificamente entre os anos de 1995 a 2018, já com a adoção do Real, propondo uma dimensão geográfica ligada ao acesso à terra e à produção da cidade, mediante a relação entre o salário mínimo e o custo de vida. Os resultados apontaram fases curtas de diminuição da precarização da qualidade de vida do trabalhador, ao longo do período estudado, seguida de novas tendências de acirramento da precarização já nos períodos atuais.

Cet article a pour but d'analyser les rebondissements des politiques économiques dans la vie du travailleur de São Paulo, en ayant comme méthodologie les analyses de Lúcio Kowarick et Milton A. Campanário (1994) concernant les conditions de vie du travailleur au cours de la période de la décennie perdue (1980). À l'instar du travail de Kowarick et Campanário (1984), celui-ci a pour but d'analyser les informations concernant l'évolution du salaire minimum, le pouvoir d'achat moyen, le nombre d'heures travaillées pour en bénéficier et l'évolution du prix du marché 
immobilier entre 1995 et 2018, les rebondissements des politiques du travail ont eu lieu au cours de la même période. En ce sens, cet article a pour but d'évaluer quelle était la qualité de vie du travailleur au cours de la période de la redémocratisation, plus particulièrement entre 1995 et 2018, lors de l'adoption du Real, en proposant une dimension géographique liée à l'accès à la terre et à la production de la ville, en comparant le salaire minimum et coût de la vie. Les résultats ont mis en évidence de courtes phases de diminution de la précarité de la qualité de vie des travailleurs au cours de la période étudiée ainsi que de nouvelles tendances d'augmentation de la précarité au cours de la période actuelle.

Este trabajo analizó los rebatimientos de las políticas económicas en la vida del trabajador paulistano, usando la metodología de los análisis de Lúcio Kowarick y Milton Campanario (1994) sobre las condiciones de vida del trabajador en la década de 1980. Basándonos en el trabajo de Kowarick y Campanario (1994), el presente trabajo busca reconocer las informaciones sobre evolución del salario mínimo, poder de compra de la canasta básica, número de horas trabajadas, la evolución del precio de la tierra entre 1995 y 2018 y los rebatimientos de las políticas laborales desarrolladas en el mismo período. En este sentido, este artículo busca evaluar cómo fue la calidad de vida del trabajador en el período de redemocratización, más específicamente entre los años 1995 a 2018, ya con la adopción de la moneda "Real", proponiendo una dimensión geográfica ligada al acceso de tierras y a la producción en la ciudad, mediante la relación entre el salario mínimo y el costo de vida. Los resultados del período analisado mostram breves períodos de reducción de la precarización de las condiciones de vida del trabajador seguido de nuevas tendências de acirramento de la precarización en el actual período.

The reflexes of the economic politics in the quality of life of the worker in Sao Paulo are analyzed, based upon the classical literature by Lucio Kowarick and Milton A. Campanário (1994) about quality way worker life conditions during the period known as "the more than lost decade (1980 years)". As in Kowarick and Campanario work, data regardind to minimum salary evolution, basic living costs, number of laboring hours to acquire the basic basket and the land price evolution during the years 1995-2018, are studied and related to the laboring public politics in this period.

In this manner, the paper focuses in the quality of life of the worker during the redemocratization period, particularly between 1995 and 2018, after the adoption of the Real (current currency), proposing a geographic dimension linked to the land access and the production in the city, by the means of the minimum salary and the living cost relationship. The results of the período analyzed exposed short period of the reduction of precarization labors'quality of life follows the new tendency of precarization on the present days.

\section{ÍNDICE}

Mots-clés: Précarité du travail, qualité de vie du travailleur, travail au cours de la redémocratisation

Keywords: Labor precariousness, Labor quality of life, Labor in redemocratization Palavras-chave: Precarização do trabalho, qualidade de vida do trabalhador, Trabalho na redemocratização.

Palabras claves: Precarización del trabajo, calidad de vida del trabajador, Trabajo en la redemocratización 


\section{AUTORES}

\section{CRISTIANE FERNANDES DE OLIVEIRA}

Doutora em Geografia Humana pela Universidade de São Paulo, Professora na Universidade Metropolitana de Santos, email: cfolive@hotmail.com

\section{CAMILA PINHEIRO DOS SANTOS}

Licenciada em Geografia pela Universidade Metropolitana de Santos, email: camilaapinheiro@hotmail.com

\section{PAULA VITÓRIA DE FARIA SANTOS}

Licenciada em Geografia pela Universidade Metropolitana de Santos, email: paulavitoriast@gmail.com 